\title{
The Influence of the Earthquake Disaster in Architectural Structure Design and Optimization
}

\author{
Qingying Liu ${ }^{1, a}$ \\ ${ }^{1}$ Xi'an Peihua University, Xi'an Shaanxi, China \\ a569567056@qq.com
}

Keywords: The earthquake disaster; Building structural; Design optimization

\begin{abstract}
It is very important to draw experience and lessons from the buildings having been built which had ever suffered from the earthquake disaster. Because of poor experience and seismic design. Chinese buildings like the Tangshan Earthquake and Wenchuan Earthquake has caused our country great casualties and property losses. This article mainly analyzes the earthquake disaster influence on construction, so as to provide guidance for optimization design of building structure seismic.
\end{abstract}

\section{The Basic Knowledge of Building Structure Seismic}

Cause Analysis. Induced earthquake: Due to the artificial blasting, mining and engineering activities (such as to build a small reservoir) caused by the earthquake.

The volcanic earthquake: Due to volcanic eruptions, lava violent rushed out of the ground caused by ground vibration.

Collapse earthquake: Due to the earth's surface or underground for some reason (such as a large underground cave or old mine collapse and collapse) caused by ground vibration.

Structural earthquake: As a result of the crustal tectonic activity makes the earth's crust rock formations in the weak part of the sudden rupture, dislocation caused by the earthquake.

The Cause of Tectonic Earthquake. The earth's crust is made up of plates of various sizes, "Floating on the plastic asthenosphere mantle, with the flow of the mantle material and slow moving, coupled with the earth's rotation and revolution of centrifugal force produce certain relative displacement between the plates. Because the size of the displacement of plate and the direction of each are not identical, the interaction between plates and stress in rock, when more than rock itself strength, fracture or dislocation occurs, cause earthquakes.

\section{The Structure Form of Expression and the Earthquake Hazard Analysis}

Frame Structure. The performance of frame structure in the earthquake

Survey, the earthquake zone in China's current strictly in accordance with the requirements for seismic design of frame structure building better, by earthquake damage is lighter, basically, the disaster area can see framework structure to be able to do the "big to fail", under different intensity, basic intact beam frame structure, basic does not appear to collapse. But fill walls and wall are different degrees of damage, because there is no enough rachel or invalid rachel, causing buildings collapsed filler wall cracking or hurt.

The Framework Structure of Disaster Analysis. China in recent years, most of the frame structure in the earthquake has failed to achieve "strong column weak beam" design. According to the seismic damage investigation and analysis, this paper mainly has the following several reasons:

1. The influence of the non structural components such as the filler wall;

2. The floor of the influence of frame beams bearing capacity and stiffness increase; 
3. The frame beam span and load is too big, make beam section size increases, the percussive increase flexural bearing capacity;

4. The beam end ultra strong actual strength of the reinforcement and reinforced;

5. The axial compression ratio limit rules on the high side, column section size small;

6. The minimum reinforcement ratio and small minimum stirrup ratio;

7. Under the flame structure and structure elastic stress state is different;

8. Reliability of beams.

Due to the frame structure of "strong column weak beam" most studies on the pure frame structure, and the other factors are considered, but gave no specific norms and methods, make these factors have not been fully considered in the design.

The Bottom Frame Masonry Structure. (Hereinafter referred to as bottom frame structure of the underlying framework masonry structure) can satisfy the underlying set garage, setting up shop, etc., the upper residential requirements, building high performance-price ratio. Economic underdeveloped regions in homes and buildings are generally used this kind of structure.

\section{The Underlying Framework in the Seismic Performance of Masonry Structure}

1. The collapse of the weak layer at the bottom of the framework

Again and again under the action of the earthquake, the underlying framework will produce large accumulation of plastic deformation, and the general reinforced concrete column is difficult to achieve the deformation to meet the demand of the ductility, thus will cause serious damage to bottom.

2. Caused by improper structure set down

Due to the structure arrangement chaos, framework and brick structure lateral stiffness. Especially the first part is divided into the underlying local

Frame houses, before and after the lateral stiffness is very uneven, this kind of building damage more serious. Mainly for the bottom

Plastic hinge frame column pillars appear, the underlying bricks are serious damage, especially after the bottom half of the brick wall bearing wall

Damage is very serious.

3. The underlying framework to shift

Upper masonry structure by the load bearing wall would transmit the load to the underlying framework, the framework of masonry transformation layer change due to the load transfer path or interrupt, lead to the stress of the beam-column joints uneven, the underlying framework will produce larger torsional deformation.

In addition, the structure and layout of the structure of the complicated and diversified causes stiffness center and the center of mass is not easy to overlap, torsional vibration force structure subjected to space.

Disasters of the Underlying framework Masonry Structure Analysis. Bottom frame structure is easy to form "on the bottom is soft, top-heavy" the structure of the system. Bottom frame structure as the lateral deformation is larger, the underlying when the underlying framework of deformation exceeds the limit of concrete member, framework will be collapsed, causing buildings collapsed as a whole. Therefore, carries on the seismic performance analysis and seismic conceptual design is particularly important.

Frame Structure. Within the framework, refers to the framework of internal bearing, external for the load-bearing brick houses, including internal for single column to, multilayer frame house in that row of column to the top and the bottom only for internal frame and the upper layers within the underlying framework for the brick house, is a mixture of brick and framework of bearing structure. 
The Inner Frame Structure in the Earthquake. The multiple frame brick house in the earthquake

(1) the load-bearing brick cross wall cross diagonal crack, presents the shear strength damage; More than 9 degrees high intensity area, the collapse of cross wall broken, leading to the houses collapsed.

(2) the top end cross wall outward tilt, in severe cases, the cross wall collapsed, the studio roof collapsing, it table

Ming end cross wall with roof connection not happen out of plane stability of cell damage.

(3) vertical wall and clamps, the girder bottom and window produces horizontal crack between upper and lower side of the wall, brick masonry crushed local caving, rendering the out-of-plane bending type. The damage phenomenon, with top vertical wall occurred outside the most, extent of damage is heaviest. In addition, when the cross wall spacing is bigger, the midpoint between two cross wall outside longitudinal wall brick pile damage is heavy, light near the cross wall clamps damage. Show the horizontal deformation of the floor during the earthquake.

(4) in addition to the top and bottom side of the wall between the window on the wall outside the horizontal crack, diagonal crack also occur.

(5) the outer walls of the house Yang Angle place produce v-shaped cracks, accompanied by two-way displacement, and even corner cave.

(6) reinforced base level of the top and bottom of the inner cylinder to produce cracks, in severe cases, it alkali crisp fall,

Steel bar buckling.

(7) silicon steel girders, in close to the bearing vertical slightly oblique fine cracks.

\section{The Rule of the Earthquake Damage in Multiple Inner Frame Brick House}

1. Brick wall out-of-plane bending and the destruction of the frame column, upper back, lower light.

2. Brick wall shear failure, lower weight, the upper light.

3. Precast frame damage in heavy, cast-in-situ framework in light.

4. Precast floor damage, overall cast-in-place floor light damage.

5. The top outside longitudinal wall brick heaviest post out of plane bending damage, and with the increase of cross wall spacing

And increase, reflecting the deformation of floor levels significantly during the earthquake.

6. Brick wall damage, beam-column damage to light. That brick wall is the main component to resist lateral force, and it is

Weak part of the house.

7. Single column houses the pilaster destroy heavy brick, brick wall of the house more than double row column or row of column damage light, reflect

The strength of the floor level deformation effect, and length-width ratio is proportional to the relationship of the building.

Analysis Frame Structure in Disasters. Multiple frame brick house in the earthquake has two characteristics: one is the cross wall spacing is bigger, the height is higher, and therefore have relatively low floor stiffness, poor housing integral space effect. 2 it is the outer walls of the housing bearing structure and inner framework is made up of two kinds of brick masonry and concrete material, the stiffness and ultimate deformation value is large, the deformation of the under seismic action.

Brick with internal frame under horizontal seismic action of work can be divided into two stages: the stage of elastic deformation, due to the rigidity of brick wall outside is much bigger than inner 
frame column, the vast majority of horizontal earthquake shear shall be borne by the stiffness of large brick wall, and the share of frame column horizontal seismic action is less. Brick wall with internal frame number less than ordinary multi-story brick, brick wall damage more serious, therefore, although the frame has good seismic performance at this stage is difficult to give full play to the brick wall crack, it have larger lower stiffness, deformation of a sharp increase in house in elastic-plastic deformation stage, the internal force redistribution between the wall column, brick walls bear part of the seismic shear transfer to the framework, the internal force and deformation of framework has increased dramatically.

To sum up, in under the action of earthquake damage of masonry building with internal frame, from bricks to frame divide-and-conquer, although in a brick house with internal frame has good ductility of frame column, but under the same seismic intensity damage than multi-story brick is serious.

\section{Seismic Structure Design Suggestions}

\section{Choose Good for Seismic Field and Foundation.}

1.Should be based on engineering cases, need to master the earthquake activities of engineering geological information, good for seismic, bad and dangerous section make a comprehensive evaluation, should choose favourable areas, to avoid the bad location, effective measures should be taken when cannot avoid, should no longer be dangerous places to build a, b, c class construction

Favourable areas refers to: hard or flat open, dense homogeneous in hard land.

Bad location refers to: soft soil, liquefied soil, strip protruding spur, high-rise isolated struggle up the steep slope of the hill, the rock, river Banks and slope edge, so the river channel, fault fracture zone, etc.

Danger areas refers to: possible landslides and collapses when the earthquake, subsidence, ground fissure, landslide, and the part of the seismogenic fault zone may occur on the surface rupture, etc.

2.The same structural unit should not be set on the nature of different foundation; Unfavorable also parts adopt natural foundation, USES the pile foundation. When the foundation with soft clay layer, the liquefied soil, the newly filled soil or serious uneven soil layer should be estimated foundation uneven settlement when the earthquake or other adverse effects, and take corresponding measures. When building on a foundation that is very different, settlement joint should be set up.

3.A large number of earthquake damage show that the influence of site conditions on the building earthquake damage is bigger, the main factors of site conditions on earthquake damage is liquefied soil hardness and thickness of the ground cover. The soft soil, covering the more thick, the greater the damage, and the more light.

Classification of the construction site should be equivalent to soil shear wave velocity and ground cover layer thickness shall prevail.

The soil shear wave velocity measurement should meet the following requirements:

1.In preliminary exploration stage of the field, to a large area of the same geological unit, measuring the soil shear wave velocity, the number of drilling shall be one 5 of the drilling quantity control to a third, could reduce the mountain valley area, but not less than three.

2.Detailed investigation stage in the field, the single building, measuring the soil shear wave velocity of the drilling quantity should not be less than two, data change is bigger, can increase; In the residential area in the same geological dense high-rise buildings, measuring the soil shear wave velocity can be appropriate to reduce the number of drilling, but each building of not less than one.

3.For butyl class building and layer number is less than 10 and not more than $30 \mathrm{~m} \mathrm{c}$ class 
construction, when not the measured shear wave velocity, according to the name and the traits of geotechnical estimates of each soil layer shear wave velocity.

4.Thickness of covering layer of construction sites, shall meet the following requirements:

In general, should press the ground to the shear wave velocity is greater than the distance of 500 meters per second soil end face.

Local surface 5 meters beneath the shear wave velocity is greater than the upper adjacent soil shear wave velocity is 2.5 times of the soil, and how the shear wave velocity in this layer is not less than 400 meters per second, according to the distance of the ground to the end face.

Shear wave velocity is more than 500 meters per second of boulder, lens, should be regarded as the surrounding soil.

5.Soil layer of volcanic rock hard interlayer, shall be regarded as rigid body, its thickness should be deducted from the covering soil layer.

6.The equivalent shear wave velocity of soil layer, should press type calculation:VSE=DO/T

Building Structure Design. Building structure design should conform to the requirements of the seismic conceptual design, should not adopt a serious irregular design, serious irregular buildings can be divided into irregular plane and vertical irregular, architecture and its resistance to lateral force of the structure of the planar appropriate rules, symmetry, and should have good integrity; The structure of the building facade and profile appropriate rules, the lateral stiffness should be uniform, the section size of vertical component to resist lateral force and the strength of materials should be reduced gradually from bottom to top, avoid the lateral stiffness and bearing capacity of structures to resist lateral force mutations. This requires architectural designers don't blindly pursue novel, unique, different.

\section{Structure of the System}

1. The structure of the system should be according to the seismic fortification of construction category, the seismic fortification intensity, building height, site conditions, foundation, structure, material and construction technology, the technology, economy and use conditions are determined.

2. The structure of the system shall meet the following requirements: should have a clear diagram calculation and reasonable seismic action traditional experience. Should be avoided because of the part of the structure or component damage and led to the loss of seismic capacity of the whole structure or loss of the idea of gravity load bearing capacity, should possess the necessary aseismic bearing capacity, good ability of deformation and the ability to consume the earthquake energy. Possible weak positions, measures should be taken to improve the anti-seismic ability.

The system of structure is still should meet the following requirements:

1. Should have a multichannel seismic line

2. Should have a reasonable distribution of stiffness and bearing capacity, avoid local extinction or mutagenesis weak positions, or too much stress concentration deformation concentration.

3.The dynamic characteristics of the structure to the two major axis should be similar.

4.Masonry structure should be set up by the regulation of reinforced concrete ring beam and structural sex, core column, or adopting reinforced masonry, etc

5.Concrete structures should be reasonably choose size

Configuration vertical bearing steel bar and stirrup, avoid shear broken before bending failure, concrete crushing damage prior to yield steel bar, steel bar anchoring bond damage before the component damage.

6.Prestressed concrete component to resist lateral force, should be equipped with enough of prestressed reinforcement.

7. Steel structures should be reasonable control size, avoid the local buckling or whole 
instability.

8 node failure, should not be prior to other connection components.

9. Embedded parts of anchor damage and should not be before fitting.

10. Prefabricated structures of connection, should be able to guarantee the integrity of the structure and prestressed concrete members prestressed, appropriate anchored outside the node in the core area.

11. In order to ensure the seismic safety of structure, according to the specific situation, should follow the strong connection between structural unit or effective separation method, the structure of the high-rise building unit should be taken to strengthen the connection method.

12. As far as possible, set up multi-channel seismic measures, after a strong earthquake with many earthquakes, only line of defense, after the first damage suffered aftershocks, the structure of the whole collapse caused by the damage accumulation. Appropriate treatment, the strength of the relationship between structural elements in the form of multi-channel line under the action of earthquake, and consider a line break, cause the influence of the internal force redistribution, is to improve the seismic performance of structures, the effective measures to avoid major earthquakes.

13.Reasonable decorate component to resist lateral force, reduce the torsion effect under the action of earthquake. Bearing capacity of structure stiffness along the building height should be uniform, continuous distribution, avoid to cause weakness or weak parts of the structure.

14.Structures should possess the necessary bearing capacity, stiffness, stability, ductility and energy dissipation performance. The ductility of the main component should have a higher energy consumption and appropriate stiffness, under vertical load should not be the main components as main wall-beam.

15.Reasonably control the structural inelastic, and master the structure of the submission process, realize reasonable yield mechanism.

16. Take effective measures to prevent premature bar slip, concrete shear failure and crushing destroy fragile fracture.

17. The main structure system of housing should be according to the height of the different structural system strictly control structure and aspect ratio.

18. The encrypt parts of the wall, column, beam steel must be strictly.According to the specification requirements

\section{The Structures}

1. The structures, including architectural structures and accessory electrical and mechanical equipment, itself and its structure main body connection, should carry on the seismic design.

2. Attached to the floor, roof structure on the structures, should have a reliable connection with main body and anchorage, avoid collapsed during the earthquake hurt or broken important equipment

3. The fence wall and partition wall should be taken into account for the negative impact of the aseismic avoid unreasonable setup and result in the main structure of the damage.

4. The curtain wall, decorative cover and connect with main structure should be reliable, avoid off cuts during the earthquake.

5. Installed on the construction of the auxiliary machinery, electrical equipment system support and connection, should comply with the requirement of the function of the earthquake, and shall not cause the damage of the parts. 


\section{Conclusion}

A strong earthquake caused a great many disaster to human beings. Especially since the 20th century, the world within the scope of the earthquake caused huge property losses and casualties, seriously endanger social harmony and the sustainable development. These major earthquake disasters constantly challenges the human cognitive and defense ability of earthquake disasters. Casualties and economic losses caused by the high number of studies have shown that the main cause of all without exception and housing construction, infrastructure and other various types of civil engineering of the earth's lack of aseismic capacity is closely related to, or even seismic unqualified civil engineering is the chief culprit of the earthquake disaster. Long struggle and earthquake disasters history makes people deeply recognize the to truly reduce earthquake disasters, protect human from the earthquake threat, only we live and work in civil building environment to build more earthquake resistant. Hope this research can be more reasonable and more effective for the future development of generalized conceptual design ideas, to code for seismic design of rising levels provide a new way.

\section{Reference}

[1] About the building seismic design code of aseismic joint set discussion [J]. J Yu Changjie shanxi building. 2013 (17).

[2] The old and new building seismic design code for comparison and analysis of "strong column weak beam" [J]. J longcai, hong-biao du, Jin Ren and. Engineering and seismic strengthening reconstruction. 2012 (02).

[3] From the seismic design code of general introduction to the structure importance of seismic conceptual design $[\mathrm{J}]$. J Zhao Zhen, honoraria. Earthquake engineering and engineering vibration, 2011 (05).

[4] The Chinese traditional ancient timberwork of shallow seismic conceptual design [J]. J jun-guo dong. Heilongjiang traffic science. 2011 (04).

[5] The concept of structure in industrial architecture design [J]. J SuiXiangYu. Shanxi building. 2011 (04). 